\title{
The Studying the Adhesion Molecule P-selectin in Patients with Ischemic Heart Disease
}

\author{
Maysam Riyadh Mohammedhussein AL-aasam ${ }^{1}$, Aseel JasimShaalan AL-bdairi ${ }^{2}$, Jalal Jasim ALbdairy ${ }^{3}$ \\ 1M.B.CH.B, F.I.C.M.S. Internal Medicine, Lectural/Medical College Kufa University/Iraq, ${ }^{2}$ M.B.CH.B, MSc. \\ Physiology, PH.D. Physiology, Assistant Professor/Medical College Kufa University/Iraq, ${ }^{3}$ M.B.CH.B, C.A.B.M. \\ Internal Medicine, Alsader Teaching Hospital/Ministry of Health/Najaf/Iraq
}

\begin{abstract}
Background: P-selectin is partially responsible for the adhesion of certain leukocytes and platelets to the endothelium.

Increased levels of soluble P-selectin in the plasma have also been demonstrated in a variety of cardiovascular disorders. The aim of this study is to evaluate the role of P-selectin, in development of IHD and possible use as a biomarker and to study the change in its level after introducing of angiotensin converting enzyme inhibitor (ACEI) .
\end{abstract}

Patients and Method: The study involve(49) patients with stable IHD and 51 patient with acute coronary syndrome and (50) subjects as a control.

They divided into three groups: 1 st include subjects with no history of IHD not on (ACEI) as a control group. 2nd group include patients with history of stable IHD but not receiving any (ACEI)but on B-blocker therapy. 3rd group include patients with acute coronary syndrome not on ACEI therapy but most of them on B-blockers as a part of their treatment regimen. (ACEI) (captopril $25 \mathrm{mg}$ twice daily) was given for 1 month duration for patients in the 2 nd and 3 rd group for the 2 nd and 3rd group we measured the levels of p-selectin before and after the drug have been introduced

Result: There is increase in level of p-selectin in patients with acute coronary syndrome and to less extent in patient with stable IHD there is a decrease in the level of platelet P-selectin after introducing of ACEI in the 2nd and 3rd group.

\section{Conclusion:}

1. By comparing with control the level of p-selectin is greater in patients with acute coronary syndrome and to less extent in patient with stable IHD.

2. ACEI administration was associated with significant decrease of the level of p-selectin in patients with IHD \& to a greater extent in patient with acute coronary syndrome.

Keywords: Pselectin, platelets, IHD, angiotensin converting enzyme inhibitor.

\section{Corresponding Author:}

Maysam Riyadh Alaasam

M.B.CH.B, F.I.C.M.S. Internal Medicine, Lectural/

Medical College Kufa University/Iraq

Telephone: 00-964-7812450402

e-mail : maysam.alaasam@gmail.com

\section{Introduction}

Cardiovascular disease (CVD) is the leading cause of death for both men and women and although mortality of CVD is decreasing, CVD prevalence is increasing. More than one third of the adults currently have some form of CVD and the prevalence increases from more than $10 \%$ in those aged 20 to 39 years to more than $70 \%$ 
in those aged 60 to 79 years $\&$ about two third of men and half of women may develop CVD in their lifetime ${ }^{(1)}$.

There are many studies focus on pathogenesis of CVD which include atherosclerosis, inflammatory process \& sometimes micro embolism. these three mechanism are highly interacting with each other ${ }^{(2)}$.

Any Endothelial injury, by whatever cause, leads to Changes in platelet and endothelial cell function, these changes are considered the forerunner of the atherosclerosis of the blood vessels that occurs later which leads to many clinicalconditions like acute coronary syndrome,cerebrovascular event, peripheral vascular disease and so on ${ }^{(3)}$.

These changes lead toproduction of certain factors from the endothelium cells and platelet. which lead to Platelet-endothelium interaction $^{(4)}$.

Normal vascular "resting" endothelium represents a non-adhesive and non-thrombogenic surface that prevents adhesion of circulating platelet. In contrast, activated endothelial cells are pro-adhesive and promote the adhesion of circulating blood platelets ${ }^{(5)}$

Similar to the recruitment of leukocytes, the adhesion of platelets to the vascular endothelial surface is a multistep process, in which platelets are tethered to the vascular wall, followed by platelet rolling and subsequent firm adhesion ${ }^{(6)}$.

Adherent platelets release a variety of proinflammatory mediators that have the potential to modify signaling cascades in vascular cells, lead to release of endothelial chemo attractants. In this manner, they might mediate the adhesion and infiltration of leukocytes, in particular monocytes into the vascular wall ${ }^{(7,8)}$.

This adhesion process is mediated by many adhesion molecules, such as intercellular adhesion molecule (ICAM), vascular cell adhesion molecule (VCAM) and the selectin family of molecules (P-selectin, E-selectin and L-selectin) that play an important role in the initiation of leukocyte migration into the vascular wall ${ }^{(9,10)}$. most important one is P-selectin as the initial loose contact between circulating platelets and vascular endothelium is mediated by $\mathrm{p}$ - selectin, which ispresent on both endothelial cells and platelets.P-selectin (CD62P), the largest of the selectins, with a mass of $140 \mathrm{kDa}$, extends approximately $40 \mathrm{~nm}$ from the endothelial surface and there are about $10000 \mathrm{P}$-selectin molecules on the surface of an activated platelet ${ }^{(11)}$.
P-selectin (CD62P) is rapidly expressed on the endothelial surface in response to inflammatory stimuli by translocating from membranes of storage granules (Weibel-Palade bodies) to the plasma membrane within seconds. In addition, P-selectin is stored in platelet $\alpha$-granules and can rapidly translocate on the platelet surface upon activation. Endothelial P-selectin has been demonstrated to mediate platelet adhesion in both arterioles and venules in acute inflammatory processes, such as acutecoronary syndrome ${ }^{(12)}$.

P-selectin is also important because of its production by both platelets and endothelial cells occurring in many cardiovascular diseases aspart of the disease process including coronary artery disease, hypertension and atrial fibrillation. \& its level changing in response to certain drugs like angiotensin converting enzyme inhibitor and B-blockers,socan be use as a plasma predictor of adverse cardiovascular events and also as marker of drug effect.

P-selectin is present within both the endothelial cells and the platelets, so raised plasma levels of P-selectin reflect endothelial injury, platelet activation, or both ${ }^{(13)}$.

\section{The Aim:}

\section{The objective of the study is:}

1. To study the role of the adhesion molecule, $\mathrm{P}$-selectin, in development of ischemic heart disease and possible use as a biomarker.

2. To study the change in its level after introducing of angiotensin converting enzyme inhibitor .

\section{Patients and Method}

This is a case -control and cohort study conducted at Al-Sader medical city, in Al-Najaf Al-Ashraf city, during the period from 15th of august2014 to the 6th of January 2016.it involve(49) patients with stable IHDand 51 patients for acute coronary syndromeand (50) subjects as acontrol.

\section{The study subjects divided into three groups:}

1st include subjects with no history ischemic heart diseasenot on angiotensin converting enzyme inhibitors (ACEI) as a control group.

2nd group include patients with history of stable ischemic heart disease but not receiving any angiotensin converting enzyme inhibitor drugsbut on B-blocker therapy. 
3rd group include patients with acute coronary syndrome not on ACEI therapy but most of them on B-blockers as apart of their new treatment regimen.

Angiotensin converting enzyme inhibitordrugs (captopril $25 \mathrm{mg}$ twice daily)was given forl month duration forpatients in the 2 nd and 3rd group .

for the 2nd and 3rd groups the levels of p-selectin were measured before and after the drug have been introduced.

The patients with ischemic heart diseases were recruited from the medicine outpatient department clinic and the cardiac center and the emergency department at Al-Sader medical city.

The control group consisted of 50 volunteers who were completely healthy with no current or previous ischemic heart diseases, their age ranging between (25-50) years.

The patients with ischemic heart diseases (stable and unstable) have an age between (30-75) years.

Out of 71 patients with stable ischemic heart disease we lost contact with 22 patient and out of 69 patient with acute coronary syndrome we lost contact with 18 patient so 49 patient for stable ischemic heart disease groups and 51 patient with acute coronary syndrome were studied and compared with a 50 patients as a control .

All the patients have a detailed history and physical examination .ECG, complete blood count,lipid profile,blood urea,serum creatinine and fasting blood sugar.

All have been measured by a standard method.

Stable ischemic heart disease diagnosed by clinical signs and symptoms correlated with ECG finding.

Unstable angina and non ST elevation myocardial infarction diagnosis dependedon signs and symptoms and also positive ECG finding).
ST elevation myocardial infarction diagnosis depended clinical signs and symptoms correlated with ECG finding as a cardiac enzyme is not always available.

Exclusion criteria include any patient withthromboc ytopenia,thrombocytosis,leucopenia and leucocytosis as p-selectin is released from the platelet .

also include patients with hypertension,chronic renal failure, chronic heart failure, diabetes mellitus \& peripheral vascular disease as endothelial injury and even established atherosclerosis are usuallyexpected.

Blood collected in EDTA was mixed by inversion several times and used within 30 minutes to measure p-selectin level by ELISAand the normal level of p-selectin is $20-520 \mathrm{ng} / \mathrm{ml}$.

For fasting blood glucose, blood urea and serum creatinine Abbott architect plus C4000 autoanalyzere used.

Statistical Analysis: By using the statistical package for social sciences (SPSS) software for windows data of all participants (cases and controls) were entered and analyzed with appropriate statistical tests .

Level of significance (P .value) of $<0.05$ indicate a significant difference.

\section{The Results}

Demographic Characteristic: Female represent $55 \%$ of controls, $58 \%$ of patient with stable ischemic heart disease and $61 \%$ of patients with acute coronary syndrome while male represent $45 \%, 42 \%$ and $39 \%$ respectively.

Mean age for control is 45.32 years and for stable ischemic heart disease is 58.4 years and for acute coronary syndrome is 55.67 years as shown in figure 1 : 


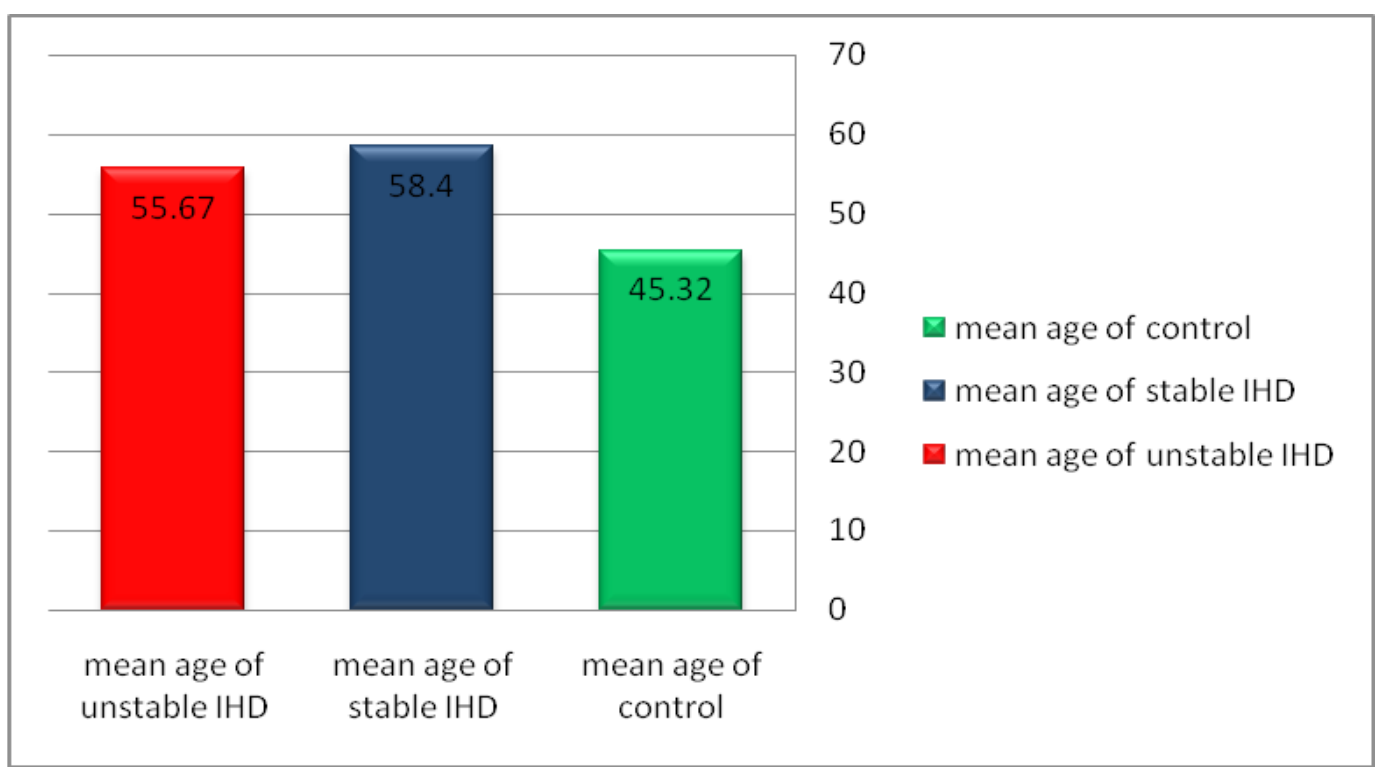

Figure 1: Showing comparison among the three groups according to age.

\section{Comparative Measurement:}

A-measurement of p-selectin in patient with IHD and control:

The level of p-selectin in patient with stable IHD in comparison with control shown in table 1:

Table 1: Show the comparison between the level of p-selectin of control subjects and stable ischemic heart disease and patient with acute coronary syndrome.

\begin{tabular}{|l|c|c|c|c|}
\hline & $\begin{array}{c}\text { Control Group } \\
\mathbf{N = 5 0}\end{array}$ & $\begin{array}{c}\text { Stable IHD Group } \\
\mathbf{N = 4 9}\end{array}$ & $\begin{array}{c}\text { ACS Group } \\
\text { N=51 }\end{array}$ & \multirow{2}{*}{ P value } \\
\cline { 2 - 4 } & Mean \pm SD & Mean \pm SD & Mean \pm SD & \\
\hline P-selectin Level $(\mathrm{ng} / \mathrm{ml})$ & $134.9 \pm 111.48$ & $350.3 \pm 136.1$ & $652 \pm 137.9$ & $<0.05$ \\
\hline
\end{tabular}

The patient with acute coronary syndrome is divided to a29\% with acute ST elevation myocardial infarction and $23 \%$ of patients withnon S Televation myocardial infarction and $48 \%$ of patients is presented with unstable angina as shown in figure 2 :

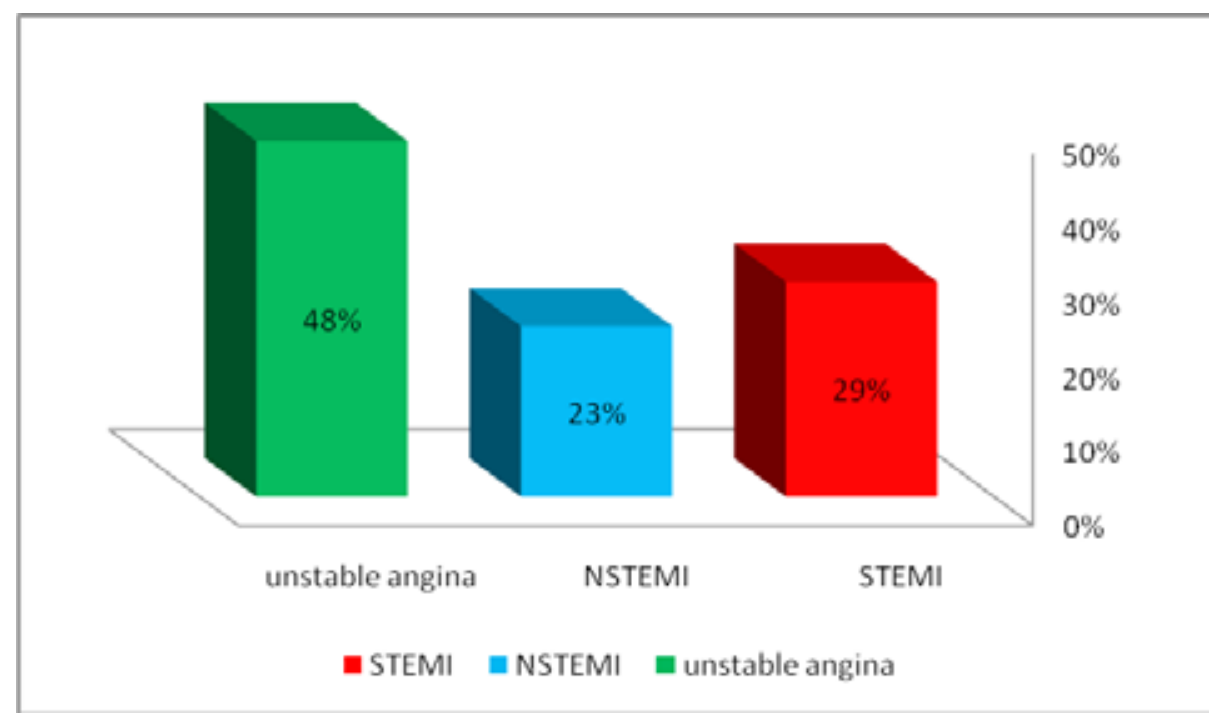

Figure 2: Show the percentage of STEMI, NSTEMI and unstable angina in acute coronary syndrome group. 
The level of p-selectin in patient with stable IHDpatiens in comparison with ACS patients shown in table 2:

Table 2: Show the comparison between the level of p-selectin of stable IHD patients and acute coronary syndrome.

\begin{tabular}{|l|c|c|c|}
\hline & $\begin{array}{c}\text { Stable IHD Group } \\
\text { N=49 }\end{array}$ & $\begin{array}{c}\text { ACS Group } \\
\text { N=49 }\end{array}$ & \multirow{2}{*}{ P value } \\
\cline { 2 - 3 } & Mean \pm SD & Mean \pm SD & \\
\hline P-selectin Level $(\mathrm{ng} / \mathrm{ml})$ & $350.3 \pm 136.1$ & $652 \pm 137.9$ & $<0.05$ \\
\hline
\end{tabular}

There is a statistically significant difference in the level of p-selectin had been found between the control and stable ischemic heart disease, as well as those with acute coronary syndrome patients ( $\mathrm{p}$-value is $<0.05$ ).

B- the comparative measurement of the level of p-selectinin patient with IHDbefore and after one month of introducing ACEI:
The level of p-selectinin patient with stable ischemic heart disease at presentation and after one month of introducing angiotensin converting enzyme inhibitor (captopril $25 \mathrm{mg}$ twice daily) is shown in figure 4:

Table 3: Show the comparison between the level of p-selectinin patient with stable ischemic heart diseaseand patient with acute coronary syndromeat presentation and after one month of introducing ACEI.

\begin{tabular}{|l|c|c|c|c|c|}
\hline & $\begin{array}{c}\text { Stable IHD Group } \\
\text { at presentation } \\
\mathbf{N = 4 9}\end{array}$ & $\begin{array}{c}\text { Stable IHD after } \\
\text { captopril treatment } \\
\text { Group N=49 }\end{array}$ & $\begin{array}{c}\text { ACS Group at } \\
\text { presentation N=51 }\end{array}$ & $\begin{array}{c}\text { ACS after captopril } \\
\text { treatment Group } \\
\text { N=51 }\end{array}$ & P-value \\
\cline { 2 - 5 } & Mean \pm SD & Mean \pm SD & Mean \pm SD & Mean \pm SD & $464.5 \pm 130.9$ \\
\hline $\begin{array}{l}\text { P-selectin Level } \\
(\mathrm{ng} / \mathrm{ml})\end{array}$ & $350.3 \pm 136.1$ & $216.9 \pm 111$ & $652 \pm 137.9$ & $<0.05$ \\
\hline
\end{tabular}

The level of p-selectin in patient with stable IHD in comparison with patient withacute coronary syndrome after one month of introducing angiotensin converting enzyme inhibitor (captopril $25 \mathrm{mg}$ twice daily)as shown in table 4 .

Table 4: Show comparison between patients with stable IHD and patients with ACS one month after ACEI introducing.

\begin{tabular}{|l|c|c|c|}
\hline & $\begin{array}{c}\text { Stable IHD after captopril } \\
\text { treatment Group N=49 }\end{array}$ & $\begin{array}{c}\text { ACS after captopril treatment } \\
\text { Group N=49 }\end{array}$ & \multirow{2}{*}{ P-value } \\
\cline { 2 - 3 } & Mean \pm SD & Mean \pm SD & \\
\hline P-selectin Level $(\mathrm{ng} / \mathrm{ml})$ & $216.9 \pm 111$ & $464.5 \pm 130.9$ & $<0.05$ \\
\hline
\end{tabular}

According to the above results there is a statistically significant decrement in the levels of p-selectin in patient with stable ischemic heart disease after one month of introducing angiotensin converting enzyme inhibitor (captopril $25 \mathrm{mg}$ twice daily) .

Also there is a decrease in the level of p-selectin in patient with acute coronary syndrome (changing from abnormal level to normal level) after one month of introducing angiotensin converting enzyme inhibitor (captopril $25 \mathrm{mg}$ twice daily).

\section{Discussion}

Platelet activation resulting from vascular injury is important in the pathogenesis and clinical outcome of acute coronary syndromes. ${ }^{(14,15,16)}$ 
P-selectin is release from $\alpha$-granules in the membrane of resting platelets that is expressed only on the platelet surface during vascular injury so surface P-selectin may be considered as a marker of platelet activation. $^{(17,18,19,20,21)}$

In the present study we measured the level of P-selectin in normal (control) subjects who have no history of ischemic heart disease, hypertension, chronic renal failure, chronic heart failure, diabetes mellitus \& peripheral vascular disease and any platelets disorder and showed that the level was near the lower limit of normal value.

and also measurement the level of p-selectin in pt with chronic stable ischemic heart disease and showed that there is significant change in compare tocontrol although not exceeding the uppernormal value.

3rd group, patients with acute coronary syndrome (unstable angina,non ST elevation myocardial infarction and ST elevation myocardial infarction), showed that the level of p-selectin was significantly elevated.

We noticed that in patients with chronic stable ischemic heart disease the level of p-selectin is decrease to lower level than before captopril introducing.

While patient, with acute ischemic heart disease, the level of p-selectin is decreased to a lower level than before ACEI introducing but the decrement was greatercompared with stable IHD, these decrement may be related to stabilization of vascular wall or may be due to introducing of B-blocker,which show a decremental effect on p-selectin level in many studies ${ }^{(22)}$ or the decrement may related to captopril introducing.

But the decrement in the level of $\mathrm{p}$ selectin in $\mathrm{pt}$ with chronic stable ischemic heart disease after captopril introducingwas mostly related to the drug introduced, as most of these patients is already taking B-blocker as long term treatment.

Our results suggest that platelet activation as well as vascular endothelial injury play arole in pathogenesis of atherosclerosis and atherosclerotic IHD.P-selectin may be used as a marker for occurrence and progression of IHD.

Our studies are agree with many studies ${ }^{(22,23,24)}$ have shown that the increase levels of P-selectin in patients with acute coronary syndrome may be due to plaque rupture and thrombus formation, as well as to an interaction of platelets by activated leukocytes before plaque disruption, so P-selectin level couldbe used as a marker of plaque destabilization in unstable angina

Besides the role of endothelial P-selectin in monocyte recruitmentto the atherosclerotic lesionsome other studies pointed to involvement of platelet $\mathrm{P}$-selectin on progression of atherosclerosis

\section{Conclusion}

1. By comparing the level of $p$-selectin is greater in patients with acute coronary syndrome and to less extent of patient with stable ischemic heart disease.

2. Angiotensin converting enzyme inhibitor administration was associated with significant decrease of the level of $p$-selectin even to agreater extent in patient with acute coronary syndrome

Conflicts of Interest: None of the authors have any conflicts of interest relevant to this reaserch subject.

Ethical Clearance: The study was conducted in accordance with ethical principles that have their origin in the Declaration of Helsinki .The study protocol, care of patients and subject information were reviewed and approved by a local Ethic committee.

\section{Source of Funding: Self}

\section{Reference}

1. Libby P. Inflammation in atherosclerosis. Nature 2002;420:868-874

2. Hansson GK. Inflammation, atherosclerosis and coronary artery disease. N Engl J Med2005;352:1685-1695

3. Davi G, Patrono C. Platelet activation and atherothrombosis. N Engl J Med 2007;357:24822494

4. Borissoff JI, Heeneman S, Kilinc E, et al. Early atherosclerosis exhibits an enhanced procoagulant state. Circulation 2010;122:821-830

5. Furie B, Furie BC. Mechanisms of thrombus formation. N Engl J Med 2008;359:938-949

6. Ruggeri ZM. Platelets in atherothrombosis. Nat Med 2002;8:1227-1234

7. Topol EJ. Toward a new frontier in myocardial reperfusiontherapy: emerging platelet preeminence. Circulation 1998;97:211-8.

8. Michelson AD. Flow cytometry: a clinical test of 
plateletfunction. Blood 1996;87:4925-36.

9. Michelson AD, Furman MI. Laboratory markers of plateletactivation and their clinical significance. CurrOpin Hematol 1999;6:342-8.

10. Ault KA, Cannon CP, Mitchell J, et al. Platelet activation inpatients after an acute coronary syndrome: results from theTIMI-12 trial. Thrombolysis in Myocardial Infarction. J AmColl Cardiol1999;33:634-9.

11. Blann AD, Lip GYH. Hypothesis: is soluble P-selectin a newmarker of platelet activation? Atherosclerosis 1997;128:135-8.

12. Manka D, Collins RG, Ley K, et al. Absence of P-selectin, but not intercellular adhesion molecule-1, attenuates neointimal growth after arterial injury in apolipoprotein e-deficient mice. Circulation 2001;103:1000-5.

13. Huo Y, Schober A, Forlow SB, et al. Circulating activated platelets exacerbate atherosclerosis in mice deficient in apolipoprotein E. Nat Med 2003;9:61-67

14. Chung I, Choudhury A, Lip GY. Platelet adhesion in congestive heartfailure. Thromb Res 2008;121:885-8.

15. Monroe DM, Hoffman M, Roberts HR. Platelets and thrombin generation. ArteriosclerThrombVasc Biol 2002;22:1381-1389

16. Gurbel PA, Gattis WA, Fuzaylov SF, Gaulden L, Hasselblad V, Serebruany VL, et al. Evaluation of platelets in heart failure: Is platelet activity related to etiology, functional class, or clinical outcomes? Am Heart J 2002;143:1068-75.

17. Gawaz M, Langer H, May AE. Platelets in inflammation and atherogenesis. J Clin Invest2005;115:3378-3384

18. Massberg S, Brand K, Gruner S, et al. A critical role of platelet adhesion in the initiation of atherosclerotic lesion formation. J Exp Med 2002;196:887-896

19. Weber C. Platelets and chemokines in atherosclerosis: partners in crime. Circ Res2005;96:612-616

20. Gleissner CA, von Hundelshausen P, Ley $\mathrm{K}$. Platelet chemokines in vascular disease.Arterioscler Thromb Vasc Biol 2008;28:1920-1927

21. Rizvi M, Pathak D, Freedman JE, Chakrabarti S. CD40-CD40 ligand interactions in oxidative stress, inflammation and vascular disease. Trends Mol Med 2008;14:530-538

22. Atalar E, Haznedaroglu Y, Aytemir K, et al. Circulating adhesion molecules in patients with stable coronary artery disease. Int $\mathrm{J}$ Hematol2000;72:507-11.

23. Draz N, Hamdy MS, Gomaa Y, et al. Soluble $\mathrm{P}$-selectin is a marker of plaque destabilization in unstable angina. Egypt J Immunol 2003;10:83-7.

24. Dong ZM, Brown AA, Wagner DD. Prominent role of P-selectin in the development of advanced atherosclerosis in apoE-deficient mice. Circulation 2000;101:2290-5. 